\title{
Enhancement of aged and denatured fingerprints using the cyanoacrylate fuming technique following dusting with amino acid-containing powders
}

Article

Accepted Version

Nixon, C., Almond, M. J., Baum, J. V. and Bond, J. W. (2013) Enhancement of aged and denatured fingerprints using the cyanoacrylate fuming technique following dusting with amino acid-containing powders. Journal of Forensic Sciences, 58 (2). pp. 508-512. ISSN 0022-1198 doi:

https://doi.org/10.1111/1556-4029.12052 Available at https://centaur.reading.ac.uk/32309/

It is advisable to refer to the publisher's version if you intend to cite from the work. See Guidance on citing.

To link to this article DOI: http://dx.doi.org/10.1111/1556-4029.12052

Publisher: Wiley-Blackwell

All outputs in CentAUR are protected by Intellectual Property Rights law, including copyright law. Copyright and IPR is retained by the creators or other copyright holders. Terms and conditions for use of this material are defined in the End User Agreement. 


\section{www.reading.ac.uk/centaur}

\section{CentAUR}

Central Archive at the University of Reading

Reading's research outputs online 
Enhancement of Aged and Denatured Fingerprints using the Cyanoacrylate Fuming Technique following Dusting with Amino Acid-Containing Powders.

Carly Nixon, $\mathrm{MSc}^{1}$, Matthew J. Almond, DPhil ${ }^{1}$, John V. Baum, $\mathrm{PhD}^{1}$ and John W. Bond, DPhil $^{2}$

1. Department of Chemistry, University of Reading, Whiteknights, Reading RG6 6AD, UK

2. Department of Chemistry, University of Leicester, Leicester LE1 7RH, UK

\begin{abstract}
We have carried out experiments to investigate the ageing of latent fingerprints deposited on black PVC over a period of 4-15 weeks. A thumbprint was used in each case and before deposition of the print the donor rubbed their thumb around their nose to add sebaceous deposits. We have studied the effect of heat, light and moisture and we find that moisture is the most significant factor in the degradation of the latent print. We have attempted to enhance these latent prints by dusting with valine powder or powders composed of valine mixed with gold or red fluorescent commercial fingerprint powders. In order to make a direct comparison between "treated" and "untreated" prints, the prints were cut in half with one half being "treated" and one not. Our studies show the best results being obtained when powders of valine and red fluorescent powders are applied prior to cyanoacrylate fuming.
\end{abstract}

Keywords: forensic science, latent fingerprint, fingerprint regeneration, cyanoacrylate fuming, amino acid, valine, fingerprint degradation 


\section{Introduction}

The use of the cyanoacrylate ("superglue") fuming method (CFM) for latent fingerprint visualisation on non-porous surfaces such as glass and plastic is a common choice for forensic scientists. On contact with the fingerprint the cyanoacrylate polymerises to give a white deposit (1) which may be enhanced by a range of dyes, sometimes with viewing under UV or visible light; a common method being to use yellow dye and to view with excitation at $450 \mathrm{~nm}$ (2). Much work has been done on the polymerisation of cyanoacrylates in solution but there is less information regarding the polymerisation of cyanoacrylate vapour on contact with fingerprint residue (3). However, the process is believed to be anionic and to be initiated by a nucleophile $(1,3)$ Many nucleophiles will initiate the polymerisation - indeed it is suggested that all nucleophiles with the exception of $\mathrm{Cl}^{-}$ion (3) can act in this way. It is possible that water, which exists in small amounts in the fingerprint, may act as the nucleophile, initiating the polymerisation process.

As a fingerprint ages its chemical content changes. This leads to it being less effective in initiating cyanoacrylate polymerisation (1). A simple explanation for this may be evaporation of water, although atmospheric oxidation and microbiological degradation of components have also been invoked as possible causes (4). Although a small amount of water is thought to be helpful in initiating polymerisation $(1,3)$ too much leads to a less efficient reaction; certainly latent fingerprints washed in water do not easily give good images when developed with cyanoacrylate (4). This may be because other components of the fingerprint which are necessary to initiate the cyanoacrylate polymerisation reaction are lost by washing.

There have been a small number of studies to attempt to regenerate denatured latent fingerprints which may then be developed by cyanoacrylate fuming. Wargacki et al. in 2007 
(3) and 2008 (1) found that both lactate ion and alanine could enhance the quality of fingerprints developed in this way. They concluded that it was the carboxyl group of these reagents that acted as the nucleophile. In 2008 [1] they followed up this work by exposing latent prints to the vapour over glacial acetic acid or ammonia "880" solution. They found that both of these reagents significantly enhanced the print quality and that exposure to the acetic acid or ammonia vapour for around 10 minutes followed by 12 minutes exposure to cyanoacrylate vapour gave optimum results. The mechanism for this enhacement is not fully clear although it appears that either ammonia or the carboxylate group in acetic acid may act as nucleophiles. It is also clear that the fingerprints are being exposed to small amounts of water during this process which may also act as a nucleophile. By contrast, Czekanski et al. showed that exposing prints to sodium lactate or alanine solution (n.b., lactate ion or amino acids are possible initiators of cyanoacrylate polymerisation in eccrine sweat) did not lead to any formation of polymer upon fuming. In this case it is possible that the excess of water has inhibited the polymerisation for the reasons discussed above.

With these studies in mind we have tested a dusting method for latent print regeneration by cyanoacrylate fuming. We chose to study powders containing the very non-polar amino acid valine which has an isopropyl $\left(-\mathrm{CH}\left(\mathrm{CH}_{3}\right)_{2}\right)$ side chain. Our rationale for this choice was that non-polar, oily components of the latent prints are likely to survive more readily upon ageing. The non-polar amino acid can interact with these, and the amino acid can then provide nucleophilic centres to initiate polymerisation. A second aim of our work was to study the ageing process such as exposure to heat, light and moisture, all of which have been reported to be important in the degradation of latent prints and to assess the relative importance of these processes in latent print degradation $(1,3,4)$. In this way we wished to compare our results to recent work by DePaoli et al. who have demonstrated that lactic acid - the major polymerisation initiator in superglue fuming - shows photochemical and thermal degradation. 
By contrast neither amino acids nor urea show photo-degradation, although both begin to thermally decompose above $100{ }^{\circ} \mathrm{C}(5)$. The degradation product of lactic acid, pyruvic acid, is also found to photodegrade. These photodegradation processes are enhanced by the presence of iron oxides, which occur at low levels in fingerprints. Such processes are believed to account for significant differences in fingerprint ageing between dark and light storage conditions (5). We also note recent work in which methylamine pretreatment of dry latent fingerprints on polyethylene leads to enhanced detection by cyanoacrylate fuming and we wished to compare our results using amino acids against this work (6).

\section{Experimental Section}

Fingerprints were collected from two individuals onto black PVC "pond-liner" plastic. The pond liner was cut into individual pieces of $7 \times 5 \mathrm{~cm}$ in size. This was washed with pure deionised water then blotted dry with a paper towel. Once the plastic was completely dry a thumbprint was applied. A thumbprint was used in each case to ensure consistency of measurements. Before placing the print onto the plastic the print donor rubbed their thumb around the nose area before placing the print. The donor did not wash their hands before starting this procedure, but they replenished the sweat on the thumb between each print by rubbing again around the nose area. One print was deposited every five minutes, but nothing was done to enhance the amount of eccrine sweat, e.g., wearing latex gloves between depositing prints. This procedure was adopted was to try to give the most natural and realistic condition of a fingerprint deposited at a crime scene, i.e., that no washing prior to deposition was employed, that no artificial enhancement of sweating was used and that sebaceous and eccrine deposits would be mixed. However, it is noted that such prints will be significantly oily to a greater extent than many fingerprints.

Prints were then subject to ageing for periods of 4,7 or 15 weeks as follows:- 
Ambient: the prints were stored in an open tray in an office, by a closed window and in natural light.

Dark: the prints were stored in an open tray in a cupboard where the doors were kept closed at all times.

Dark desiccator: the prints were stored in a desiccators in a cupboard where the doors were kept closed at all times.

Refrigerator: the prints were stored in a sealed container in a refrigerator. A thermometer was used to periodically record the temperature which was found to be $3{ }^{\circ} \mathrm{C}+/-1{ }^{\circ} \mathrm{C}$.

Oven: the prints were stored in a small fan-assisted thermostated oven set to $40{ }^{\circ} \mathrm{C}$.

The prints were then cut in half; one half was dusted with either pure valine powder or valine powder mixed with commercial "gold fluorescent" or "red fluorescent" fingerprint powder containing about $10 \%$ valine, the other half had no pretreatment. Valine powder (stated purity 99\%) was used as supplied by Aldrich Chemical Company. Gold and red fluorescent fingerprint powders were used as supplied by Crime Scene Investigation Equipment Ltd. Both halves were then subjected to fuming with cyanoacrylate ("superglue") vapour either in Department of Chemistry, University of Reading or Northamptonshire Police Headquarters. At Reading a large beaker was placed on a stirrer hotplate. Contained within the beaker was a watch glass with cyanoacrylate and a small beaker containing saturated potassium chloride solution. The fingerprint halves were suspended at the top of the beaker which was covered with a large watch glass and heated to $65{ }^{\circ} \mathrm{C}$ (the boiling point of cyanoacrylate). The potassium chloride was present to add humidity - at $65{ }^{\circ} \mathrm{C}$ it is known to give a relative humidity of $79.9+/-0.5 \%$ (7). At Northampton a large commercial fuming chamber $(2 \times 1.5$ x $0.7 \mathrm{~m}$ ) which was fully thermostated and whose humididty was controlled was utilised. 
The humidity was set to $78.9 \%$ for our experiments. Prints were typically exposed to cyanoacrylate vapour for 12 minutes.

All prints apart from those prints where gold or red fluorescent powder had been employed were then dyed in a $0.004 \mathrm{~mol} \mathrm{~L}^{-1}$ solution of Basic Yellow dye BY40 (supplied by Crime Scene Investigation Equipment Ltd.). Prints were then viewed and photographed using an optical microscope under excitation at $450 \mathrm{~nm}$ for Basic Yellow dyed prints or under broad band UV excitation for prints where gold or red fluorescent powders had been used.

\section{Results and Discussion}

The amino acid valine was selected for use in this study. This was chosen because it is very non-polar. According to the Hessa scale (8) which assigns negative numbers to the most hydrophobic acids valine has a hydrophobicity index of -0.31 . It should be noted that other hydrophobicity scales for amino acids exist which give a positive number to the most hydrophobic amino acids (9). In the first series of experiments a set of 15 fingerprints (1 to 15) were taken by the method described above. The prints were then subject to various ageing methods for periods of 4 (prints 1 to $\mathbf{5}$ ), 7 (prints $\mathbf{6}$ to 10) or 15 (prints $\mathbf{1 1}$ to 15) weeks as listed in Table 1. The prints were then cut in half. One half was dusted with valine powder only, the other half was left untreated. Both halves of the print were then exposed to superglue vapour for 12 minutes with the superglue heated to $65{ }^{\circ} \mathrm{C}$. The prints were then dyed with BY40 fluorescent dye and viewed under UV light under an optical microscope, this method was found to give very clear images from the fluorescent dye. Each half of the print was then "scored" in terms of its quality using the Bandey (10) five point scale (see Table 2). It may be seen (Table 1) that several prints show measurable enhancement - these are $2,3,4,5,7,9$ and 15. Some interesting points emerge. Print 3 is illustrated in Figure 1. 
Storing the print in a desiccator clearly causes it to "age" more slowly (compare prints $\mathbf{2 , 7}$ and 12 with 1, 6 and 11). This is in line with the view that ageing is caused by loss of watersoluble components, especially amino acids which are involved in the superglue polymerisation reaction; storage under dry conditions helps to slow down this process. Storage in the dark also appears to prolong the life of the print (see prints $\mathbf{3}, \mathbf{8}$ and $\mathbf{1 3}$ ) although after 15 weeks storage the quality of this print has declined more than that of the equivalent print (12) stored in a desiccator. It is perhaps expected that storage in a refrigerator at $3{ }^{\circ} \mathrm{C}$ (prints 4,9 and 14 ) would prolong the print's life; perhaps less expected is the fact that storage in an oven at $40{ }^{\circ} \mathrm{C}$ (prints $\mathbf{5 , 1 0}$ and $\mathbf{1 5}$ ) also appears to preserve the print. The most likely explanation for this is that the oven provides a drier environment. Generally high-quality prints were produced for dark-desiccator, dark, refrigerator and ovenstored prints when powdering with valine, followed by cyanoacrylate fuming is employed. A final set of experiments were carried out on 15-week old prints, but the superglue fuming, dyeing and observation of the prints was carried out at the fingerprinting laboratory of the Northamptonshire Police Headquarters, Wootton Hall, Northampton (prints 16 to 25). This allowed more reproducible and rigorous conditions to be used. It will be seen that (table 1) the differences from the experiments where fuming was carried out at Reading are small (compare prints $16 / 17$ with $11,18 / 19$ with $12,20 / 21$ with $13,22 / 23$ with 14 and $24 / 25$ with 15). Again the ambient-stored prints give poor images and the best enhancement is for desiccator-stored prints. The problem at this stage in our work was that ambient-stored prints, i.e., those most clearly representing a scene of crime situation do not preserve well and are difficult to enhance.

In order to attempt to facilitate this enhancement we added commercially-available red fluorescent or gold fingerprint powder to the valine. Powders containing about $9 \%$ valine were made up and one half of the print was dusted with this. Both halves of each print were 
then exposed to cyanoacrylate vapour heated to $65{ }^{\circ} \mathrm{C}$ for 10 minutes. The powdered half was viewed under visible (gold-dusted) or UV (red fluorescent-dusted) light. These conditions were employed because gold-dusted prints were found to give good images under visible light which were not noticeably enhanced by UV excitation. By contrast red- dusted prints gave much poorer images under visible light but were significantly enhanced by UV excitation. The un-dusted half was treated with BY40 fluorescent dye and viewed under UV light. The findings are listed in Table 3. The most obvious result is the clear enhancement of ambient-stored prints (prints 26 and 27). Both gold-dusted (prints 26, 28, 30, 32 and 34) and red-dusted (prints $\mathbf{2 7}, \mathbf{2 9}, \mathbf{3 1}, \mathbf{3 3}$ and $\mathbf{3 5}$ ) powders gave a good enhancement and the prints developed well. Print $\mathbf{3 5}$ is illustrated in Figure 2. The identical half of the print without enhancement did not develop so well. Apart from print 29 (which in any case is clearly of poor quality) all other prints showed some degree of enhancement.

There are clearly problems of reproducibility in any fingerprint experiment. The exact conditions of print deposition have a large bearing on the results obtained, as do the volunteer giving the print and exact conditions of temperature etc which may influence sweating. As such it is often difficult to make exact comparisons. However, our results suggest that more attention could be given to powdering methodology to enhance prints via the "superglue" fuming technique. Our results build upon those previously obtained by Wargacki et al. $(1,3)$ where ammonia and acetic acid vapour were found to significantly enhance print development using the cyanoacrylate method. It is likely to be the presence of nucleophilic centres within the amino acid that facilitates the process. In our experiments the amino acid probably sticks to the oily deposits within the print, and then facilitates the polymerisation of the superglue. It is possible that purely eccrine prints, which have less oily content, may not give such positive results. However, it should be noted that purely eccrine prints are unlikely 
to left at a crime scene. As mentioned previously our aim here was to reproduce "natural" albeit oily - fingerprints as closely as possible.

Three further points of note emerge from our studies. First that storage of latent prints in desiccators prolongs their life and leads to better images when cyanoacrylate fuming is to be employed. Second that higher temperatures do not appear to affect the lifetime of the print as much as might be expected. This is probably because the higher temperatures are accompanied by dryer conditions (6). Both of these findings suggest that water may not be the most important nucleophile in initiating cyanoacrylate polymerisation. This point is in line with previous studies by Wargacki et al. who concluded that water is not a nucleophile for cyanoacrylate fuming but rather acts as a solvating component for the hygroscopic initiators. Water only produces oligomers of no significant molecular weight, not polymers and does not lead to fingerprint development.

From our results it is possible to propose an overall optimum procedure for print enhancement based on the following observations. When valine-dusted prints were treated with BY40 dye we found a slight advantage in using $450 \mathrm{~nm}$ excitation under an optical microscope rather than broad-band UV excitation. Broad-band UV excitation was used in some cases, however, because of availability of apparatus and gave satisfactory results. When fluorescent powders were used we found that gold powder gave better images under visible light but that these were only marginally enhanced by UV excitation. Red fluorescent powder gave less clear images under visible light (because of the darker colour of the powder) but they were enhanced by UV excitation. Overall the use of red fluorescent powder with UV excitation gave the clearest images. 
The overall optimum protocol therefore for enhancement of a print is as follows. Dust the print with a mixture of red fluorescent powder and valine containing about $10 \%$ valine. Subject the print to cyanoacrlate fuming, then view by fluorescence under UV excitation.

It is, of course, possible that purely eccrine and sebaceous prints behave differently with respect to traces of water; this is a point that could be explored further in future work. Finally we note that that exposure of light appears to cause some acceleration of the degradation process. The best preserved prints are those kept in dark, dry conditions.

\section{Acknowledgements}

We are grateful to Alexander Withycombe and Jade Rayner for carrying out some preliminary experiments.

\section{References}

1 Wargacki SL, Lewis LA Dadmun MD, Enhancing the Quality of Aged Latent Fingerprints Developed by Superglue Fuming: Loss and Replenishment of Initiator. J. Forensic Sci. 2008; 53, 1138-1144.

2 Morimoto S, Kaminogo A Hirano T, A New Method to Enhance Visualisation of Latent Fingermarks by Sublimating Dyes and its Practical Use with a Combination of Cyanoacrylate Fuming, Forensic Sci Int 1998; 120: 172-176.

3 Wargacki SL, Lewis LA Dadmun MD, Understanding the Chemistry of the Development of Latent Fingerprints Developed by Superglue Fuming 2007; 52: $1057-1062$.

4 Czekanski P, Fasola M Allison J, A Mechanistic Model for the Superglue Fuming of Latent Fingerprints, J. Forensic Sci 2006; 51: 1323-1328. 
5 DePaoli G, Lewis SA, Schuette EL, Lewis LA, Connatser RM Farkas T, Photo- and Thermal-Degradation Studies of Select Eccrine Fingerprint Constituents, J. Forensic Sci., 2010, 55, 962-969.

6 McLaren C, Lennard C Stoilovic M, Methylamine Pretreatment of Dry, Latent Fingermarks on Polyethylene for Enhanced Detection by Cyanoacrylate Fuming, J. Forensic Identification, 2010, 60, 199-222.

7 Equilibrium Relative Humidity: Saturated Salt Solutions, 2003-2009: Data available from Omega.com (www.omega.com/temperature/z/pdf/z.103.pdf) Last accessed August 2011.

8 Hessa T, Recognition of Transmembrane Helices by the Endoplasmic Reticulum Transclon, Nature 2005; 433: 377-381.

$9 \quad$ Kyte J and Doolittle RF, A Simple Method for Displaying the Hydrophobic Character of a Protein J. Molec. Biol. 1982; 157: 105; Wimley WC and White SH, Experimentally Determined Hydrophobicity Scale for Proteins at Membrane Surfaces, Nature Struct. Biol. 1996; 3: 842.

10 Bandey HL, Fingerprint Development and Imaging Newsletter: The Powders Process, Study 1, Sandridge: Police Scientific Development Branch, Home Office; Report No. 54/04, 2004.

11 Wargacki SP, Lewis LA Dadmun MD, Understanding the Chemistry of the Development of Latent Fingerprints by Superglue Fuming, J. Forensic Sci, 2007, 52, 1057-1062. 
Table 1 - The Bandey Five-Point Scale for Grading of Ridge Detail on Fingerprints (10)

\begin{tabular}{|l|l|}
\hline Grade & Comment \\
\hline 0 & No Development \\
\hline 1 & No continuous ridges; all discontinuous or dotty \\
\hline 2 & One third of mark continuous ridges; rest no development or dotty \\
\hline 3 & Two thirds of mark continuous; rest no development or dotty \\
\hline 4 & Full development; whole mark continuous ridges \\
\hline
\end{tabular}

Table 2 - Grading of Prints using the Bandey Scale (10) obtained using cyanoacrylate fuming following various ageing procedures for 4, 7 or 15 weeks. One part of each print has been enhanced by dusting with valine powder before development.

\begin{tabular}{|l|l|l|l|l|l|}
\hline Print Number & $\begin{array}{l}\text { Ageing } \\
\text { Treatment }\end{array}$ & Age/Weeks & $\begin{array}{l}\text { Powdered } \\
\text { Side Grade }\end{array}$ & $\begin{array}{l}\text { Unpowdered } \\
\text { Side Grade }\end{array}$ & Difference \\
\hline 1 & Ambient & 4 & 1 & 1 & 0 \\
\hline 2 & $\begin{array}{l}\text { Dark } \\
\text { Desiccator }\end{array}$ & 4 & 4 & 2 & 2 \\
\hline 3 & Dark & 4 & 4 & 3 & 1 \\
\hline 4 & Refrigerator & 4 & 4 & 2 & 2 \\
\hline 5 & Oven & 4 & 3 & 2 & 1 \\
\hline 6 & Ambient & 7 & 4 & 4 & 0 \\
\hline 7 & $\begin{array}{l}\text { Dark } \\
\text { Desiccator }\end{array}$ & 7 & 4 & 3 & 1 \\
\hline 8 & Dark & 7 & 3 & 3 & 0 \\
\hline 9 & Refrigerator & 7 & 4 & 3 & 1 \\
\hline
\end{tabular}




\begin{tabular}{|l|l|l|l|l|l|}
\hline 10 & Oven & 7 & 4 & 4 & 0 \\
\hline 11 & Ambient & 15 & 1 & 1 & 0 \\
\hline 12 & $\begin{array}{l}\text { Dark } \\
\text { Desiccator }\end{array}$ & 15 & 4 & 4 & 0 \\
\hline 13 & Dark & 15 & 1 & 1 & 0 \\
\hline 14 & Refrigerator & 15 & 3 & 3 & 0 \\
\hline 15 & Oven & 15 & 3 & 2 & 1 \\
\hline 16 & Ambient & $15 \mathrm{a}$ & 1 & 1 & 0 \\
\hline 17 & $\begin{array}{l}\text { Dark } \\
\text { Desiccator }\end{array}$ & $15 \mathrm{a}$ & 0 & 0 & 0 \\
\hline 18 & Dark & $15 \mathrm{a}$ & 4 & 2 & 2 \\
\hline 19 & Refrigerator & $15 \mathrm{a}$ & 4 & 4 & 0 \\
\hline 20 & Oven & $15 \mathrm{a}$ & 1 & 1 & 0 \\
\hline 21 & Ambient & $15 \mathrm{a}$ & 1 & 1 & 0 \\
\hline 22 & $\begin{array}{l}\text { Dark } \\
\text { Desiccator }\end{array}$ & $15 \mathrm{a}$ & 4 & 4 & 0 \\
\hline 23 & Dark & $15 \mathrm{a}$ & 4 & 4 & 0 \\
\hline 24 & Refrigerator & $15 \mathrm{a}$ & 2 & 1 & 1 \\
\hline 25 & Oven & $15 \mathrm{a}$ & 2 & 1 & 1 \\
\hline
\end{tabular}

A - Superglue fuming carried out using facilities at the fingerprinting laboratory at Northamptonshire Police Headquarters.

Table 3 - Grading of Prints using the Bnadey Scale (10) obtained using cyanoacrylate fuming following various ageing procedures for 4 weeks. One part of each print has been enhanced by dusting with powder containing $10 \%$ valine in "gold" or "red" fluorescent commercial fingerprint powder before development.

\begin{tabular}{|l|l|l|l|l|l|l|}
\hline $\begin{array}{l}\text { Print } \\
\text { Number }\end{array}$ & $\begin{array}{l}\text { Ageing } \\
\text { Treatment } \\
\text { Powder }\end{array}$ & $\begin{array}{l}\text { Fluorescent } \\
\text { Age/Weeks }\end{array}$ & $\begin{array}{l}\text { Powdered } \\
\text { Side } \\
\text { Grade }\end{array}$ & $\begin{array}{l}\text { Unpowdered } \\
\text { Side Grade }\end{array}$ & Difference \\
\hline 26 & Ambient & Red & 4 & 4 & 1 & 3 \\
\hline
\end{tabular}




\begin{tabular}{|l|l|l|l|l|l|l|}
\hline 27 & Ambient & Gold & 4 & 3 & 0 & 3 \\
\hline 28 & $\begin{array}{l}\text { Dark } \\
\text { Desiccator }\end{array}$ & Red & 4 & 3 & 0 & 3 \\
\hline 29 & $\begin{array}{l}\text { Dark } \\
\text { Desiccator }\end{array}$ & Gold & 4 & 0 & 0 & 0 \\
\hline 30 & Dark & Red & 4 & 3 & 0 & 3 \\
\hline 31 & Dark & Gold & 4 & 2 & 1 & 1 \\
\hline 32 & Refrigerator & Red & 4 & 4 & 3 & 1 \\
\hline 33 & Refrigerator & Gold & 4 & 4 & 3 & 1 \\
\hline 34 & Oven & Red & 4 & 2 & 1 & 1 \\
\hline 35 & Oven & Gold & 4 & 4 & 1 & 3 \\
\hline
\end{tabular}

